Review Article

\title{
The Biomarkers for Acute Myocardial Infarction and Heart Failure
}

\author{
Xi-Ying Wang, Fen Zhang, Chi Zhang, Liang-Rong Zheng $\mathbb{D}$, and Jian Yang $\mathbb{D}$ \\ Department of Cardiology, The First Affiliated Hospital, College of Medicine, Zhejiang University, Hangzhou, China \\ Correspondence should be addressed to Liang-Rong Zheng; 1191066@zju.edu.cn and Jian Yang; 1313027@zju.edu.cn
}

Received 1 September 2019; Revised 5 November 2019; Accepted 4 December 2019; Published 17 January 2020

Academic Editor: Claudio De Lucia

Copyright ( $2020 \mathrm{Xi}$-Ying Wang et al. This is an open access article distributed under the Creative Commons Attribution License, which permits unrestricted use, distribution, and reproduction in any medium, provided the original work is properly cited.

\begin{abstract}
The use of a large number of cardiovascular biomarkers, meant to complement the use of the electrocardiogram, echocardiography cardiac imaging, and clinical symptom assessment, has become a routine in clinical diagnosis, differential diagnosis, risk stratification, and prognosis and guides the management of patients with suspected cardiovascular diseases. There is a broad consensus that cardiac troponin and natriuretic peptides are the preferred biomarkers in clinical practice for the diagnosis of the acute coronary syndrome and heart failure, respectively, while the roles and possible clinical applications of several other potential biomarkers are still under study. This review mainly focuses on the recent studies of the roles and clinical applications of troponin and natriuretic peptides, which seem to be the best-validated markers in distinguishing and predicting the future cardiac events of patients with suspected cardiovascular diseases. Additionally, the review briefly discusses some of the large number of potential markers that may play a more prominent role in the future.
\end{abstract}

\section{Introduction}

According to the World Health Organization (WHO), cardiovascular disease (CVD) is the number one cause of death globally and is responsible for $45 \%$ of all deaths, equating to $>4$ million deaths per year in Europe [1]. Its high morbidity, mortality, and high rate of rehospitalization have forced a number of researchers to search for the best way to diagnose, stratify risk, and manage patients with suspected cardiovascular diseases, among which acute coronary syndrome (ACS) and heart failure (HF) are most commonly studied. Acute coronary syndrome, usually caused by decreased coronary artery perfusion due to stenosis or distal embolization of the thrombus [2] and sudden total occlusion of a coronary artery by thrombosis, typically presents with the main symptoms of acute chest pain and persistent STsegment elevation in an electrocardiogram (ECG). However, there are a small number of patients without obvious symptoms or changes in the ECG. Thus, the measurement of a number of cardiac biomarkers is urgently needed to help with early diagnosis, risk stratification, and management of acute coronary syndrome. Heart failure is the terminal stage of a wide range of cardiovascular diseases that result in the decompensation of the heart's ability to contract or relax, also defined as a clinical condition with typical symptoms and signs [3]. The pathophysiological process involves the release of a series of factors, hormones, and proteins into the bloodstream, which could subsequently be used as diagnostic biomarkers.

Classically, biomarkers, such as cardiac troponin and the natriuretic peptides (NPs), associated with acute coronary syndromes and heart failure, respectively, play an important role in routine clinical practice. The ideal biomarker for detecting myocardial injury needs to be expressed at relatively high levels within cardiac tissue, with high clinical sensitivity and specificity that is detectable in the blood early after the onset of symptoms, such as chest pain [4]. As there are numerous cardiac biomarkers, it is useful to classify biomarkers into various pathophysiologic groups, such as myocardial ischemia or necrosis, inflammation, hemodynamics, angiogenesis, atherosclerosis, or plaque instability [5]. Cardiac troponin (cTn), expressed as three similar isoforms ( $\mathrm{I}, \mathrm{C}$, and $\mathrm{T}$ ), is the biomarker of choice for the diagnosis of myocardial necrosis because it is the most 
sensitive and specific biochemical marker of myocardial ischemia/necrosis available [6]. It has been demonstrated that plasma cTn content is elevated in many cardiovascular diseases other than acute myocardial infarction, including acute or chronic heart failure, aortic dissection, myocarditis, takotsubo cardiomyopathy, atrial fibrillation, and stroke [7]. The mechanisms underlying the release of cTn into the bloodstream are believed to include cell turnover, myocyte apoptosis, necrosis and reversible injury, increased cell membrane permeability, and release of cardiac troponin degeneration products $[7,8]$. Studies have also shown that membranous blebs enable the release of cardiac troponin in response to ischemia without necrosis [9]. Among the isoforms, the most specific markers for acute coronary syndromes are cardiac troponin I (cTnI) and cardiac troponin $\mathrm{T}(\mathrm{c} \operatorname{Tn} \mathrm{T})$, the elevations of which have become a predominant indicator for acute myocardial infarction (AMI) [10] and are considered the "gold standard" in AMI diagnosis.

Natriuretic peptides (NPs), composed of three structurally similar peptides, that is, atrial natriuretic peptide (ANP), B-type (or brain) natriuretic peptide (BNP), and $\mathrm{C}$-type natriuretic peptide (CNP), play an important role in cardiovascular disease [11] and are elevated to a large extent in response to increased wall stretching due to volume or load stress in HF. BNPs play a critical role in maintaining homeostasis in the cardiovascular system, serving as counterregulatory hormones for volume and pressure overload [12]. The levels of blood BNP and the N-terminal pro-B-type natriuretic peptide (NT-proBNP) are widely measured in clinical applications for the diagnosis, risk stratification, and management of patients with heart failure, as they are the closest to optimal biomarker standards for clinical implications in HF [13]. Higher natriuretic peptide levels increase the likelihood that the etiology of dyspnea is due to HF [14].

We performed PubMed and Web of Science searches for original studies and screened reference lists to identify possible relevant studies by searching the literature from 2003 to 2019. Search terms were "biomarker," "new biomarker," "B-type natriuretic peptide," "cardiac troponin," "C-reactive protein," "copeptin," "endothelial cell-specific molecule 1," “interleukin-6," “inflammatory medium," "cardiac myosin-binding protein C," "gene expression biomarkers," "heart-type fatty acid binding protein," "platelet related biomarkers," "transmembrane and soluble isoforms," "cystatin C," "microRNA," "acute coronary disease," "coronary artery disease," "heart failure," "non-STelevation acute coronary syndrome," etc. Studies were included if they were prospective, retrospective, randomized controlled trials or animal models.

This article will provide an overview of cardiac biomarkers, mainly focusing on the recent studies of the role and applications of cTn and NPs in the diagnosis, risk stratification, and management of patients with acute coronary syndromes and heart failure. Additionally, this article reviews some biomarkers related to acute coronary syndromes and heart failure that may have potential clinical value in the future.

\section{The Most Popular and Effective Biomarkers}

2.1. Cardiac Troponin. The cTn complex is one of the components of the thin filament and it plays a significant role in the regulation of muscle contraction. This complex is composed of three isoforms, namely, cTnC, which binds $\mathrm{Ca}^{2+}$, cTnI, which inhibits the ATPase activity of actomyosin, and cTnT, which interacts with actomyosin. cTn mediates the interaction between actin and myosin and thereby regulates cardiomyocyte contraction [15]. cTnI and cTnT are the two isoforms expressed in the cardiac muscle only (cTnC is also expressed in the skeletal muscle), and they have been verified to be specific and sensitive biomarkers of myocardial damage [16-18], which is particularly important in asymptomatic patients, when combined with other biomarkers and examinations [19]. Many researches have proved that cTn is a more sensitive and specific marker of cardiomyocyte injury than creatine kinase $(\mathrm{CK})$, its $\mathrm{MB}$ isoenzyme (CK-MB), and myoglobin [17]. In clinical practice, high-sensitivity cTn (hs-cTn) assays are recommended over sensitive cTn or traditional cTn [16-18, 20] because they enable accurate quantification of troponin in most healthy people [21]. In addition, the hs-cTn assay presents a superior prognostic performance in the non-STelevation acute coronary syndrome (NSTE-ACS), compared to the commercial fourth-generation cTnT assay $[22,23]$.

cTn is an integral criterion in the diagnosis of AMI. According to the 2015 European Society of Cardiology (ESC) guidelines for NSTE-ACS, the measurement of a biomarker of cardiomyocyte injury, preferably hs-cTn, was mandatory in all patients with suspected NSTE-ACS [20]. This can serve to confirm the diagnosis in symptomatic patients with diagnostic electrocardiographic changes [24]. An undetectable level of hs-cTn at presentation has a high negative predictive value and allows the rapid rule-out of AMI in patients with acute chest pain [25]. The elevation of hs-cTn usually occurs within 3-12 hours and persists for 5-14 days after the onset of symptoms in patients with AMI [4]. Data from several large multicenter studies have consistently shown that hs-cTn assays increased the accuracy of the AMI diagnosis at the time of presentation to the emergency department (ED) $[16,20,26]$. Blood levels of hs-cTn must be evaluated at the time when patients come into ED with the complaint of chest pain. If the level is over the upper limit of normal (ULN) or the pain persists no more than 6 hours, especially without typical changes in ECG, hs-cTn should be retested [20]. When the initial level is above ULN or the retest level is increased accompanied by typical changes in the ECG, the patient should be treated as soon as possible because the diagnosis of AMI is highly suspected. However, if the initial level of hs-cTn is normal, the time interval to the second cardiac troponin assessment remains controversial. For rapid rule-out in AMI patients with hs-cTn, two alternative approaches using the $0 \mathrm{~h} / 1 \mathrm{~h}$ algorithm or $0 \mathrm{~h} / 3 \mathrm{~h}$ algorithm have been adequately validated and may be considered [20]. It has been confirmed that the addition of the 1h-hs-cTn measurement significantly promotes the diagnostic accuracy in the patients with mild cTn elevation [27]. The ESC recommended that the rule-in using the $0 \mathrm{~h} / 3 \mathrm{~h}$ algorithm has a high positive predictive 
value, while the sensitivity remains too low for clinical use [28]. However, increasing age reduces the rule-in accuracy of the $0 \mathrm{~h} / 1 \mathrm{~h}$ algorithm, and therefore, a modest increase in the cut-off point is recommended which can still maintain the rule-out safety [29]. With regard to the gender factor, researches have demonstrated that the gender-specific hs-cTnT cut-off point only has modest influence compared to the age factor [30]. Another study showed that the downward adjustment of hs-cTn thresholds in women may be warranted to reduce the underdiagnosis of acute myocardial infarction in women [31]. It was also confirmed that revised cut-offs for hscTnT based on age and gender only improve the diagnostic performance rather than the prognostic risk prediction for death or other adverse events [32].

One report has shown that while hs-cTnT and hs-cTnI seem to have comparable diagnostic accuracies, hs-cTnI had greater early diagnostic accuracy [33]. That suggests that hscTnI can be examined separately to rule-in or rule-out patients in time if possible in the advanced analytical technique. Additionally, another study showed that the hs-cTnT blood concentration exhibited a diurnal rhythm, characterized by gradually decreasing concentrations throughout the daytime, rising concentrations during nighttime, and peak concentrations in the morning [34]. The rhythm does not seem to affect the diagnostic accuracy for AMI, except for screening purposes. hs-TnI does not seem to express the same rhythm, it demonstrates high diagnostic accuracy for AMI, and it does not differ with time of presentation [35].

Beyond diagnostic utility, cTn levels provide prognostic information in predicting short- and long-term outcomes based on clinical and ECG variables. Numerous studies have demonstrated a strong independent relationship between cTn and prognosis [36]. Meta-analysis indicated that in patients with NSTE-ACS the short-term odds of death were increased three- to eightfold for patients with an abnormal troponin test, and in patients with suspected ACS, those who had a negative troponin test had an overall mortality between $0.7 \%$ (troponin I, cohort studies) and $2.1 \%$ (troponin I, trial studies) [36]. However, unlike in the diagnosis of AMI, frequent and serial measurements are not necessary, because an isolated measurement on the first postoperative day is enough to identify high-risk subgroups, and changes of hs-cTn do not seem to further improve risk stratification beyond initial presentation values [26]. In the study by Shah et al., almost two-thirds of the patients with suspected ACS could have been discharged with very few cardiac events, using the standard of cTn concentration of less than $5 \mathrm{ng} / \mathrm{L}$ [21]. However, for those who are well within the normal reference interval, increasing cTn concentrations is positively associated with adverse cardiovascular outcomes in primary prevention populations [37]. Both hs-cTnI and hscTnT were predictive for all-cause mortality. Notably, hscTnT measurement showed superior prognostic performance in predicting long-term all-cause mortality compared with hs-cTnI [38].

2.2. BNP or NT-proBNP. BNP is synthesized and released by cardiac ventricular cells in response to volume or pressure overload [39]. Both active BNP and inactive NT-proBNP are generated from the cleavage of proBNP and therefore they are secreted into the bloodstream in equal concentrations [40]. While ANP is stored as the preform in the intracellular granules, BNP is predominantly synthesized when triggered by extracellular stimuli. After secretion into the bloodstream, the BNP will then bind to NP receptors (NPRs) and subsequently activate the intracellular cGMP signaling cascades to reduce the volume or pressure overload. BNP is primarily cleared through the degradation by neutral endopeptidases and partially through the uptake by NPR and renal excretion [41]. BNP and NT-proBNP, the two most commonly used natriuretic peptides, play a diagnostic role in the assessment of heart failure [42]. They may be increased due to systolic and/or diastolic dysfunction, left ventricular hypertrophy, valvular heart disease, ischemia, or a combination of these factors [43]. In multiple logistic-regression analyses, the measurements of B-type natriuretic peptide added significant independent predictive power to other clinical variables in models predicting which patients had congestive heart failure, with an odds ratio of 29.60. It is suggested that BNP is the best single predictor of a final diagnosis of HF, compared to individual history, physical examination, chest X-ray, and laboratory findings [44]. Furthermore, the BNP level in the bloodstream has a predictive role for cardiovascular risk in the general population and BNP itself could serve as a therapeutic target for cardiovascular diseases, including hypertension, heart failure, and myocardial infarction [45].

Guidelines recommend the use of BNP or NT-proBNP in the diagnostic algorithm for $\mathrm{HF}$, especially for the patients whose echocardiography was not found to have an important cardiac abnormality [46], with higher levels indicating a higher likelihood for AHF to be the main cause of acute dyspnea [47]. These tests help doctors rule out heart failure quickly and identify those who would benefit from additional confirmatory tests, typically echocardiography, or making echocardiography unnecessary $[3,48]$. As the 2016 European Society of Cardiology guidelines for HF recommend, the upper limit of normal in the nonacute setting for BNP is $35 \mathrm{pg} / \mathrm{mL}$ and for NT-proBNP it is $125 \mathrm{pg} / \mathrm{mL}$; in the acute setting, higher values should be used (BNP, $100 \mathrm{pg} / \mathrm{mL}$, NTproBNP, $300 \mathrm{pg} / \mathrm{mL}$, and mid-regional pro-A-type natriuretic peptide (MR-proANP), $120 \mathrm{pmol} / \mathrm{L}$ ) [46]. However, a cutpoint of $\mathrm{BNP} \leq 54 \mathrm{pg} / \mathrm{mL}$ is recommended for ruling out $\mathrm{CHF}$ in severely obese patients $(\mathrm{BMI} \geq 35)[49,50]$, which indicates that the cut-off points varied among different populations, including the elderly, obese patients, patients with renal disease, and even nonacute patients. According to the 2016 European Society of Cardiology guidelines for HF, when a patient comes into the ED with nonspecific symptoms and signs, such as breathlessness, ankle swelling, and fatigue, there are two alternative paths for clinicians, either echocardiography first or BNP/NT-proBNP first. Because both BNP/NTproBNP and echocardiography have limitations and the guidelines recommend using them in different situations, it was still worthy of scientific research to explore the association between them Roberts et al. concluded that there was no statistical difference between the diagnostic accuracy of 
plasma BNP and NT-proBNP, though NT-proBNP had a longer half-life than BNP, and that the measurement of MRproANP may also be a valuable rule-out test for HF $[44,51]$, which is rarely measured in the current clinical practice. The reason may be that the measurement of ANP in plasma is hampered by marked instability of the hormones, reminding us that biochemical research into detecting the proANP-derived peptides is still worthy of attention [42].

In addition to their utility in HF diagnosis, the levels of BNP or NT-proBNP are remarkably useful for risk stratification and management of patients with suspected HF. In HF management, the trend of decreasing levels of natriuretic peptide indicates effective management strategies [52]. Recently, Troughton et al. reported that for patients aged $<75$ years with chronic heart failure $(\mathrm{CHF})$, with or without impaired left ventricular systolic function, NP-guided treatment can decrease the all-cause mortality and readmission rate compared with clinically guided therapy, even with its potential to unexpectedly induce or exacerbate concomitant disorders [53]. Across the wide range of $\mathrm{HF}$, even at-risk patients, concentrations of BNP and NTproBNP also have prognostic value [44]. NT-proBNP can improve the prediction of heart failure in patients with type 2 diabetes [54]. In Piercarlo Ballo's study, the author measured 1012 asymptomatic subjects with systemic hypertension and/or type 2 diabetes with no clinical evidence of $\mathrm{HF}$ and concluded that NT-proBNP measurement could provide more information for the prediction of clinical outcome in asymptomatic, stage A-B HF hypertensive and diabetic patients [55]. Furthermore, several studies have established that BNP or NT-proBNP also had strong associations with adverse cardiovascular outcomes in a variety of primary prevention and general populations [37]. In addition, assessment of risk stratification is particularly important in planning end-of-life care for patients and when making the decision to undergo surgery (including transplantation) [3]. Previous meta-analyses have suggested that a single elevated preoperative NP measurement was highly predictive of serious cardiovascular complications after noncardiac surgery [56], and a recent study has indicated that the addition of a postoperative NP measurement significantly improved the prediction of the mortality or nonfatal MI within 30 days or $\geq 180$ days after noncardiac surgery [57]. All these potential functions for the detection of BNP/NT-proBNP levels still need large randomized multicenter trials to better explore this personalized approach to care.

2.3. Combined Use of cTn and BNP/NT-proBNP. Both cTn and BNP are quantitative markers of cardiac damage and widely applied in clinical diagnosis, risk stratification, and management of patients with or without cardiovascular diseases. BNP, widely used for the diagnosis and risk stratification of patients presenting with suspected heart failure, may sometimes be measured after an ACS in order to identify patients at high risk and low risk of adverse outcomes [4]. In patients with NSTE-ACS, NT-proBNP has good and comparable predictive value for 30 -day mortality [58].
In James and his coworkers' research, they measured BNP in samples obtained three days after the onset of ischemic symptoms in 2525 patients and found that BNP could provide predictive information for use in risk stratification across the spectrum of acute coronary syndromes, such as the risk of new or recurrent myocardial infarction [24]. CTn, commonly used for the diagnosis and risk stratification in patients presenting with suspected ACS, is sometimes measured to help in determining the etiology or trigger of acute HF (AHF). However, there is considerable overlap in cTn levels from AHF without AMI versus AHF with AMI [47]. Age, renal function, diabetes, hypertension, and a history of heart failure have all been reported as determinants of circulating cTnT concentrations $[19,59,60]$. One report has suggested that the levels of NT-proBNP and hs-cTnT may be useful adjuncts to clinical assessment and that both provide much more prognostic information than the total cholesterol or high-sensitivity C-reactive protein levels in this cohort of patients with type 2 diabetes [61]. The prognostic accuracy of the Global Registry of Acute Coronary Events (GRACE) score was improved when combined with three individual biomarkers including hsTnT, NT-proBNP, and high-sensitivity C-reactive protein (hs-CRP) in patients with acute coronary syndrome [62]. However, another study suggested that a dual-biomarker strategy combining the detection of cTn and BNP does not promote the diagnostic accuracy of inducible cardiac ischemia [63].

\section{Other Clinical Biomarkers}

Both cTn and BNP/NT-proBNP are definitive biomarkers of ACS, but they are not enough. Therefore, it is necessary to explore more markers to facilitate earlier and appropriate diagnosis, risk stratification, and management of patients. Moreover, using one or two biomarkers to define the complex pathophysiology of heart failure is inadequate and novel biomarkers are still required for the diagnosis and management of cardiovascular diseases. However, because the literature on the variety of cardiac biomarkers in clinical practice is too large to summarize in one article, this article only focuses on some useful and routine biomarkers.

3.1. C-Reactive Protein (CRP). CRP is a useful prognostic indicator in patients with ACS, as elevated CRP levels are independent predictors of cardiac death, AMI, and congestive heart failure [4]. It is the most widely used inflammatory marker in routine clinical practice. Nonetheless, CRP is a less specific and sensitive biomarker of cardiac injury compared to hs-cTn. Reynoso-Villalpando et al. found that the CRP level was significantly increased in ACS patients compared to the patients without a personal history of ischemic cardiomyopathy [64]. Not only outpatient but inpatient departments often use hs-CRP to assess the outcome in patients with heart disease, such as in MI and ACS [65].

3.2. Copeptin. Copeptin, the c-terminal part of the vasopressin prohormone that is released together with arginine 
vasopressin (AVP) within 0-4 h after symptom onset [66], observably improves baseline cTn sensitivity and could improve effectiveness and safety in combination with cTnT or cTnI for early rule-out of AMI [67-71] without serial testing in comparison to cTn alone [72]. Besides its function of early diagnosis, copeptin was recognized as an independent predictor for all causes of mortality in heart failure patients with reduced ejection fraction, by Pozsonyi and his coworkers [73]. However, as a nonspecific prognostic marker, other conditions could also influence the level of copeptin, such as renal disease and lower respiratory tract infections [69]. Despite this, the 2015 European Society of Cardiology guidelines for NSTE-AC recommended copeptin as a routine clinical examination to clinicians [20], which required more studies to evaluate ideal cut-off levels [69] and the precise roles. However, the high-sensitivity copeptin assay does not seem to increase the diagnostic or prognostic yield already provided by the hs-cTnT assay in the patients suspected of having myocardial infarction in the ED [74].

\section{The Emerging Biomarkers under Study}

\subsection{Inflammation Biomarkers}

4.1.1. Interleukin-6 (IL-6). IL-6, as well as CRP, is a critical inflammation biomarker that may be implicated in the diagnosis, risk stratification, and prognosis of patients with AMI. IL-6 expression is shown to be elevated in induced myocardial infarction by transcoronary ablation of septal hypertrophy, suggesting its diagnostic role [75]. Additionally, CRP and IL-6 are both significantly upregulated in acute coronary syndrome [76]. The IL-6 concentration, independent of the already established predictors, is also related to adverse cardiac events [77, 78], supporting its potential therapeutic target in unstable ischemic heart disease [78]. The IL-6 receptor antagonist could improve the inflammatory response and the percutaneous coronary intervention- (PCI-) treated cTn release in NSTEMI, and this improvement is independent of the inhibition of the endothelial cell activation [79].

4.1.2. Soluble CD40 Ligand (sCD40L). sCD40L is a molecule involved in both inflammation and the thrombosis process [80], and a study has shown that it mediates the interaction of platelets and neutrophils [81]. In addition, another study confirms that sCD40L plays a role in the vascular and endothelial dysfunction seen in AMI progression [82]. It has been demonstrated that the $s C D 40 \mathrm{~L}$ concentration is upregulated in AMI patients, accompanied by an increase of the inflammatory biomarker IL-6 and two adhesion molecules, sVCAM-1 and sICAM-1 [83]. However, there are debates over the prognostic performance in patients with ST elevation who underwent PCI. While one study showed that patients with lower sCD40L concentration present with adverse outcomes [84], another study indicates that a high sCD40L level is the cause of increased in-hospital and oneyear all-cause mortality rates [85].
4.1.3. Galectin-3 (Gal-3). Gal-3 is a member of the inflammation mediators and is related to the extent of myocardial inflammation and fibrosis, which is also negatively correlated with ventricular ejection fraction [86]. Furthermore, Gal-3 is thought to be involved in the formation, destabilization, and rupture of plaques [87]. Serum Gal-3 is related to left ventricular dilation and is a contributory factor in predicting the outcome and guiding the monitoring of patients with both acute heart failure and chronic heart failure [88-90].

4.1.4. Other Inflammatory Markers. The interleukin-37 (IL37) concentration is highly upregulated in acute coronary syndrome and elevated IL-37 baseline is related to poor outcomes [91, 92]. Lipoprotein-associated phospholipase A2 (Lp-PLA2) is another inflammation biomarker that is unsuitable for use as a therapeutic target while its plasma concentration is linked to the risk prediction of cardiovascular outcomes in patients with stable coronary heart diseases [93].

\subsection{Cardiomyocytes Injury Biomarkers}

4.2.1. Cardiac Myosin-Binding Protein C (cMyC). cMyC is one of the three isoforms of myosin-binding protein $\mathrm{C}$ expressed in the cardiac tissue whereas the other two isoforms are expressed in the skeletal muscle [94]. Following cardiomyocyte necrosis, cMyC appears in the circulation earlier compared to hs-cTn [95]. Notably, the cMyC has a higher efficacy for ruling out (safe) and ruling in patients than hs-cTn, while the diagnostic accuracy is similar [96]. Another study also demonstrates that $\mathrm{cMyC}$ has discriminatory power comparable to hs-cTn and may perform favorably early after symptom onset [97].

\subsubsection{Heart-Type Fatty Acid Binding Protein (hFABP).} $\mathrm{hFABP}$ is released from injured myocardium and may serve as a potential biomarker for AMI. The assessment of HFABP at the ED admission adds an incremental value to the initial hs-cTnT. The increase in the sensitivity and negative predictive value for patients with chest pain with noncontributive electrocardiogram could potentially allow safe and early rule-out of AMI without the need for further serial troponin testing [98]. In the patients presenting to the ED with chest pain and no cTnI elevations, hFABP showed a higher sensitivity in the diagnosis of AMI with a positive rate of $55 \%$. It is suggested that hFABP may be a good candidate for AMI rule-in/rule-out within the ED context [99]. The addition of hFABP to hs-cTn has more accuracy and accelerates clinical diagnostic decisions by identifying the patients at low risk for AMI $[100,101]$. Another study has demonstrated that hFABP has superior sensitivity than cTnI and suggests a combination use of hFABP and cTnI subsequently to diagnose AMI [102].

4.2.3. Endothelial Cell Related Biomarkers. Endothelial cellspecific molecule 1 (ESM-1), also known as endocan, is a 
biomarker for endothelial dysfunction [103] and may serve as a novel evaluation method for risk stratification of patients with acute STEMI [104]. Another study also demonstrated that high endocan level at presentation was an independent predictor for adverse cardiac events $[105,106]$.

4.2.4. Platelet Related Biomarkers. Mean platelet volume (MPV) and beta-thromboglobulin (beta-TG) are two important platelet biomarkers that may increase during platelet activation and have a higher expression in patients with coronary artery diseases [76]. High MPV value also correlates with an increased incidence of long-term adverse events, especially all-cause mortality in NSTEMI patients undergoing PCI [107]. Additionally, research demonstrates that MPV to platelet count ratio (MPV/P ratio) has a good prognostic performance in predicting the outcomes of patients with AMI $[108,109]$, which is similar to the GRACE score, with the MPV/P ratio being easier to calculate [110]. The MPV/P ratio also has superior performance compared to MPV alone in predicting adverse outcomes in patients with NSTEMI undergoing PCI primarily [110, 111]. Platelet microRNA-126 may also work as a novel biomarker for AMI; however, the low correlation between its expression and platelet activity limits its diagnostic utility [112].

\subsection{Other Biomarkers}

4.3.1. Suppression of Tumorigenicity 2 (ST2). ST2 is a member of IL-1 receptor family with two forms, namely, transmembrane (ST2L) and soluble (sST2) isoforms [113]. sST2 has been shown to have high expression in patients with acute myocardial infarction, accompanied by the elevation of GDF-15, HFABP, and suPAR, and downregulation of Fetuin A [114]. Elevated ST2 concentration is a predictor of major adverse cardiac events in ACS patients [115]. The serum ST2 level positively correlates with IL-33 and BNP levels, and all of these biomarkers are independent predictors of major adverse cardiac events in AMI patients undergoing PCI [116]. The 2017 ACCF/AHA guidelines for the Management of Heart Failure have specified ST2 receptors and galectin-3 as prognostic biomarkers for the prediction of hospitalization and death and to provide additional prognostic value in patients with HF [117]. Animal model research has confirmed that IL-33 prevents cardiomyocyte apoptosis and thereby improves cardiac function after MI [118]. Additionally, modulation of the IL-33/ ST2 signal may also exert a beneficial effect against the adverse postinfarction cardiac remodeling [119-121].

In addition to MI, sST2 also has a beneficial role in diagnosing heart failure, especially for patients with high IL33 levels [122]. Also, the sST2-assist score enables the prediction of left ventricular reverse remodeling in systolic heart failure patients $[123,124]$, and the sST2 concentration is highly related to cardiac death and readmission for worsening heart failure $[125,126]$. However, it should be noted that when adjusted for NT-proBNP, the prognostic information of baseline sST2 diminishes [127, 128]. The measurement of sST2 also contributes to the risk stratification for long-term $\mathrm{HF}$ and is superior to Gal-3, whose contribution to clinical risk factors is trivial [129].

4.3.2. Cystatin $C$ (cys-C). cys-C is generated in almost all human nucleated cells and serves as a biomarker for early renal impairment. An elevated cys- $\mathrm{C}$ level is related to impaired coronary perfusion and undesirable recovery of cardiac function in STEMI patients undergoing PCI [130] and predicting adverse outcomes [131-133]. A meta-analysis also demonstrated that increased cys- $\mathrm{C}$ concentration is positively correlated with readmission rates and all-cause mortality in HF patients [134].

4.3.3. miRNAs. miRNA-208 and miRNA-499 are solely expressed in cardiomyocytes. AMI patients exhibit significant increases in the concentrations of circulating miRNA208b and miRNA-499 compared with the health control group [135-137]. In terms of diagnosis, there is a correlation between microRNA-208b and plasma cTnT concentration. However, miR-208b provides lower diagnostic accuracy than miR-499 and hs-cTnT. miR-208b and miR-499 are inversely proportional to ejection fraction and can be used as a prognostic biomarker for left ventricular dysfunction after MI [135].

miRNA-1 and miRNA-133a are muscle-specific microRNAs that regulate cardiomyocyte growth and differentiation [138]. They are abundantly expressed in both skeletal and cardiac muscles and human cardiomyocytes and have been shown to be involved in the regulation of cardiac hypertrophy [139]. Serum miRNA-1 and mi-RNA133a levels were significantly elevated in a group of patients with unselected AMI. Circulating miRNA-133a can be used as a marker for cardiomyocyte death, and it may have functions in cardiovascular diseases [140].

4.3.4. Long Noncoding RNAs (lncRNAs). IncRNAs, as well as miRNAs, are observed to be altered in patients with myocardial infarction and may be beneficial for the diagnosis of myocardial infarction [141-143]. In addition, the plasma levels of lncRNAs are confirmed to provide prognostic information for myocardial infarction and predict future death in patients with heart failure $[144,145]$.

4.3.5. Sirtuin (SIRT). The SIRT family, comprising seven proteins (SIRT1-SIRT7), attracted attention as stress adaptors and epigenetic enzymes involved in the cellular events controlling aging-related disorders and cardiovascular disease [146]. Among sirtuins, SIRT1 is the best characterized protein for its protective roles against inflammation, vascular aging, heart disease, and atherosclerotic plaque development. A whole-genome expression analysis revealed that SIRT1 transcription levels were reduced in peripheral blood monocytes isolated from patients affected by acute myocardial infarction, unstable angina, and overall ACS. The authors also showed that SIRT1 mRNA expression was negatively associated with the gene expression of interleukine-6 [147]. SIRT1 mRNA expression was 
TABLE 1: Clinical application of biomarkers.

\begin{tabular}{|c|c|c|}
\hline Biomarker & Pathophysiology & Clinical usefulness \\
\hline hs-cTn & Myocardial injury & $\begin{array}{c}\text { Diagnostic } \\
\text { Prognostic } \\
\text { Risk stratification } \\
\text { Therapeutic guidance }\end{array}$ \\
\hline BNP/NT-proBNP & Myocyte stretch & $\begin{array}{c}\text { Diagnostic } \\
\text { Prognostic } \\
\text { Risk stratification } \\
\text { Therapeutic target } \\
\text { Therapeutic guidance }\end{array}$ \\
\hline CRP & Inflammation & Prognostic \\
\hline Copeptin & Oxidative stress & $\begin{array}{l}\text { Diagnostic } \\
\text { Prognostic } \\
\end{array}$ \\
\hline IL-6 & Inflammation & $\begin{array}{c}\text { Diagnosis } \\
\text { Prognostic } \\
\text { Risk stratification } \\
\end{array}$ \\
\hline sCD40L & Inflammation & Potential prognostic value \\
\hline Gal-3 & Hypertrophy/fibrosis & $\begin{array}{c}\text { Prognostic } \\
\text { Therapeutic guidance }\end{array}$ \\
\hline $\mathrm{cMyC}$ & Myocardial injury & Diagnostic \\
\hline hFABP & Myocardial injury & Diagnostic \\
\hline ESM-1 & Endothelial dysfunction & $\begin{array}{l}\text { Risk stratification } \\
\text { Prognostic }\end{array}$ \\
\hline MPV & - & Prognostic \\
\hline ST-2 & Hypertrophy/fibrosis & $\begin{array}{c}\text { Risk stratification } \\
\text { Prognostic } \\
\text { Therapeutic guidance }\end{array}$ \\
\hline cys-C & Myocardial injury & Prognostic \\
\hline miRNA & - & Potential diagnostic and prognostic value \\
\hline $\operatorname{lncRNA}$ & - & Potential prognostic value \\
\hline SIRT & Oxidative stress & Potential prognostic value \\
\hline TREM & Inflammation & Potential prognostic value \\
\hline GDF-15 & Apoptosis & Potential prognostic value \\
\hline PAPP-A & Myocardial injury & $\begin{array}{l}\text { Diagnostic } \\
\text { Prognostic } \\
\end{array}$ \\
\hline
\end{tabular}

BNP: B-type natriuretic peptide; cMyC: cardiac myosin-binding protein C; CRP: C-reactive protein; cys-C: cystatin C; ESM-1: endothelial cell-specific molecule 1; Gal-3: galectin-3; GDF-15: growth-differentiation factor-15; hFABP: heart-type fatty acid binding protein; hs-cTn: high-sensitivity troponin; IL-6: interleukin-6; lncRNA: long noncoding RNA; miRNA: microRNA; MPV: mean platelet volume; NT-proBNP: N-terminal probrain natriuretic peptide; PAPP-A: pregnancy-associated plasma protein-A; sCD40L: soluble CD40 ligand; SIRT: sirtuin; ST-2: suppression of tumorigenicity 2; TREML: triggering receptor expressed on myeloid cells.

significantly downregulated in the failing heart [148]. Endogenous SIRT1 plays a pivotal role in mediating the cell death/survival process and has been implicated in the pathogenesis of cardiovascular diseases.

4.3.6. Triggering Receptor Expressed on Myeloid Cells (TREML). TREMLs are important effectors of the innate immune system, and polymorphisms within genes encoding them may increase the risk of occurrence of various pathologies including cardiovascular disorders. The analysis of the whole genomic expression in the peripheral blood cell model showed that TREML4 was upregulated in the early stage of the acute coronary syndrome [149], which indicated that TREML4 might be used as a biomarker in the early stage of ACS and monitor the recovery of early myocardial ischemia [150]. TREML1 expression is upregulated in ischemic myocardium. The activated form of TREML1 can be detected in the plasma of patients with acute myocardial infarction, the concentration of which is an independent predictor of death. TREML1 genetic or pharmacological inhibition dampens myocardial inflammation and improves left ventricular function and survival [151].

\subsubsection{Growth-Differentiation Factor-15 (GDF-15).} GDF-15 is a member of the transforming growth factor- $\beta$ (TGF- $\beta$ ) cytokine superfamily that is widely expressed and may be induced in response to tissue injury. Under pathological conditions, GDF-15 can be produced by many cardiovascular and noncardiovascular cell types. Higher circulating GDF-15 levels are associated with increasing 
cardiometabolic risk factors in individuals without the overt cardiovascular disease [152]. GDF-15 expression is dramatically upregulated in cardiovascular disease, and the incidence of cardiovascular events is positively correlated with the concentration of GDF-15 [153, 154], suggesting its potential value as a disease biomarker. Meta-analysis shows that high levels of GDF-15 may increase the risk of mortality in patients with cardiovascular diseases $[155,156]$. GDF-15 is an independent predictor of all-cause mortality in ACS patients, adding incremental value to traditional risk factors and to NT-proBNP and C-reactive protein levels [157, 158].

4.3.8. Pregnancy-Associated Plasma Protein-A (PAPP-A). PAPP-A is a high molecular weight and zinc-binding metalloproteinase, and several studies have demonstrated that PAPP-A plays a role in cardiovascular diseases. PAPP-A is a sensitive, specific, and early marker for ACS diagnosis. Coronary PAPP-A levels were significantly elevated among patients at risk for cardiovascular diseases [159]. In the early stages of STEMI, the sensitivity of PAPP-A was superior to that of CK-MB and troponin T [160]. Even in cTnI-negative patients with the acute coronary syndrome, elevated PAPP$A$ can be used as an independent predictor of adverse outcomes [161]. Meta-analysis showed that PAPP-A is also an independent risk factor for all-cause mortality or cardiovascular events. Moreover, this positive correlation was not affected by the different follow-up periods, coronary artery disease types, and PAPP-A detection methods [162].

4.3.9. Others. The class II phosphatidylinositol 3-phosphate kinase (PIK3C2A) and the protein arginine methyltransferase 5 (PRMT5) expression have been verified to be downregulated in the AMI and are independent risk factors $[163,164]$. YKL-40 is a novel inflammatory biomarker in cardiovascular disease [165], and the high plasma levels of cys- $\mathrm{C}$ are associated with the spectrum of adverse outcomes and risk stratification in cardiovascular diseases [166]. There are many new biomarkers with superior sensitivity and specificity for scientists to explore, and for the known biomarkers, there is still a challenge for the scientific community to apply the information towards patient monitoring, diagnosis, or replacement of current biomarkers for cardiovascular diseases. We summarize the characteristics and clinical uses of each biomarker in Table 1.

\section{Conclusions}

Currently, clinicians typically measure either cTn or BNP/ NT-proBNP when encountering patients with suspected acute coronary syndromes or heart failure, based on the guidelines published by the European Society of Cardiology or American Heart Association [46]. Knowing patients with other system diseases, such as renal diseases and diabetes, who are at considerable risk of vascular complications especially asymptomatic cardiovascular disease, the levels of cTn or BNP/NT-proBNP should be measured regularly to assess the risk stratification and take the preventive steps in time. Perhaps the cTnT or cTnI should be measured separately from the total cTn complex, or cTn might be combined with BNP/NT-proBNP to take advantage of their surprising roles in early diagnosis or long-term prognosis in patients with ACS. The different roles and applications of cTn, BNP/NT-proBNP and others in different situations should be confirmed via various experimental research and clinical analyses. All in all, there is robust evidence to support the role of troponin and BNP as biomarkers in clinical medicine, but there could be some limitations. Thus, complementary biomarkers could be useful. We still need to identify more novel biomarkers to supplement ECG or $\mathrm{X}$-rays and provide more accurate and sensitive methods for cardiovascular disease diagnosis, risk stratification, and management.

\section{Conflicts of Interest}

The authors declare that they have no conflicts of interest.

\section{Acknowledgments}

This work was supported by the Research Fund of the Health Agency of Zhejiang Province (Project no. 2016KYB100) and Zhejiang Provincial Natural Science Foundation of China (Project nos. LZ16H020002 and LY19H020008).

\section{Supplementary Materials}

Table S1 contains a number of clinical trials evaluating the role of cardiac troponin in acute coronary heart disease. Table S2 summarizes the current clinical trials cited in the B-type natriuretic peptide topic. Table S3 summarizes the diagnostic and prognostic value of $\mathrm{C}$-reactive protein and copeptin in patients with acute myocardial infarction. Recently, some emerging biomarkers of acute myocardial infarction and heart failure have received increasing attention, and we have summarized them in Table S4. (Supplementary Materials)

\section{References}

[1] N. Townsend, M. Nichols, P. Scarborough, and M. Rayner, "Cardiovascular disease in Europe 2015: epidemiological update," European Heart Journal, vol. 36, no. 40, pp. 2673-2674, 2015.

[2] P. Libby, "Current concepts of the pathogenesis of the acute coronary syndromes," Circulation, vol. 104, no. 3, pp. 365$372,2001$.

[3] J. J. V. McMurray, S. Adamopoulos, S. D. Anker et al., "ESC Guidelines for the diagnosis and treatment of acute and chronic heart failure 2012 (vol 14, pg 803, 2012)," European Journal of Heart Failure, vol. 15, no. 3, pp. 361-362, 2013.

[4] R. P. Tiwari, A. Jain, Z. Khan et al., "Cardiac troponins I and T: molecular markers for early diagnosis, prognosis, and accurate triaging of patients with acute myocardial infarction," Molecular Diagnosis \& Therapy, vol. 16, no. 6, pp. 371-381, 2012.

[5] A. H. B. Wu, "Analytical validation of novel cardiac biomarkers used in clinical trials," American Heart Journal, vol. 169, no. 5, pp. 674-683, 2015. 
[6] K. Thygesen, J. Mair, H. Katus et al., "Group on Biomarkers in Cardiology of the, Recommendations for the use of cardiac troponin measurement in acute cardiac care," European Heart Journal, vol. 31, no. 18, pp. 2197-2204, 2010.

[7] K. M. Eggers and B. Lindahl, "Application of cardiac troponin in cardiovascular diseases other than acute coronary syndrome," Clinical Chemistry, vol. 63, no. 70, pp. 223-235, 2017.

[8] P. Garg, P. Morris, A. L. Fazlanie et al., "Cardiac biomarkers of acute coronary syndrome: from history to high-sensitivity cardiac troponin," Internal and Emergency Medicine, vol. 12, no. 2, pp. 147-155, 2017.

[9] P. E. Hickman, J. M. Potter, C. Aroney et al., "Cardiac troponin may be released by ischemia alone, without necrosis," Clinica Chimica Acta, vol. 411, no. 5-6, pp. 318-323, 2010.

[10] M. F. M. Fathil, M. K. Md Arshad, S. C. B. Gopinath et al., "Diagnostics on acute myocardial infarction: cardiac troponin biomarkers," Biosensors and Bioelectronics, vol. 70, pp. 209-220, 2015.

[11] P. M. McKie and J. C. Burnett Jr., "Rationale and therapeutic opportunities for natriuretic peptide system augmentation in heart failure," Current Heart Failure Reports, vol. 12, no. 1, pp. 7-14, 2015.

[12] A. S. Maisel, J. M. Duran, and N. Wettersten, "Natriuretic peptides in heart failure: atrial and B-type natriuretic peptides," Heart Failure Clinics, vol. 14, no. 1, pp. 13-25, 2018.

[13] G. Loncar, D. Omersa, N. Cvetinovic, A. Arandjelovic, and M. Lainscak, "Emerging biomarkers in heart failure and cardiac cachexia," International Journal of Molecular Sciences, vol. 15, no. 12, pp. 23878-23896, 2014.

[14] A. Maisel, C. Mueller, K. Adams Jr. et al., "State of the art: using natriuretic peptide levels in clinical practice," European Journal of Heart Failure, vol. 10, no. 9, pp. 824-839, 2008.

[15] I. A. Katrukha, "Human cardiac troponin complex. Structure and functions," Biochemistry (Moscow), vol. 78, no. 13, pp. 1447-1465, 2013.

[16] C. Mueller, "Biomarkers and acute coronary syndromes: an update," European Heart Journal, vol. 35, no. 9, pp. 552-556, 2014.

[17] K. Thygesen, J. Mair, E. Giannitsis et al., "How to use highsensitivity cardiac troponins in acute cardiac care," European Heart Journal, vol. 33, no. 18, pp. 2252-2257, 2012.

[18] K. Thygesen, J. S. Alpert, and A. S. Jaffe, "Third universal definition of myocardial infarctionm," Journal of the American College of Cardiology, vol. 61, no. 5, p. 598, 2013.

[19] P. Collinson, "The role of cardiac biomarkers in cardiovascular disease risk assessment," Current Opinion in Cardiology, vol. 29, no. 4, pp. 366-371, 2014.

[20] M. Roffi, C. Patrono, J.-P. Collet et al., "2015 ESC guidelines for the management of acute coronary syndromes in patients presenting without persistent ST-segment elevation: task force for the management of acute coronary syndromes in patients presenting without persistent ST-segment elevation of the European society of Cardiology (ESC)," European Heart Journal, vol. 37, no. 3, pp. 267-315, 2015.

[21] A. S. V. Shah, A. Anand, Y. Sandoval et al., "High-sensitivity cardiac troponin I at presentation in patients with suspected acute coronary syndrome: a cohort study," The Lancet, vol. 386, no. 10012, pp. 2481-2488, 2015.

[22] J. Grinstein, M. P. Bonaca, P. Jarolim et al., "Prognostic implications of low level cardiac troponin elevation using high-sensitivity cardiac troponin T," Clinical Cardiology, vol. 38, no. 4, pp. 230-235, 2015.
[23] M. Magnoni, G. Gallone, F. Ceriotti et al., "Prognostic implications of high-sensitivity cardiac troponin T assay in a real-world population with non-ST-elevation acute coronary syndrome," IJC Heart \& Vasculature, vol. 20, pp. 14-19, 2018.

[24] J. A. de Lemos, D. A. Morrow, J. H. Bentley et al., "The prognostic value of B-type natriuretic peptide in patients with acute coronary syndromes," New England Journal of Medicine, vol. 345, no. 14, pp. 1014-1021, 2001.

[25] M. Rubini Giménez, R. Hoeller, T. Reichlin et al., "Rapid rule out of acute myocardial infarction using undetectable levels of high-sensitivity cardiac troponin," International Journal of Cardiology, vol. 168, no. 4, pp. 3896-3901, 2013.

[26] P. Haaf, T. Reichlin, R. Twerenbold et al., "Risk stratification in patients with acute chest pain using three high-sensitivity cardiac troponin assays," European Heart Journal, vol. 35, no. 6, pp. 365-375, 2014.

[27] J. Boeddinghaus, T. Reichlin, T. Nestelberger et al., "Early diagnosis of acute myocardial infarction in patients with mild elevations of cardiac troponin," Clinical Research in Cardiology, vol. 106, no. 6, pp. 457-467, 2017.

[28] J. W. Pickering, J. H. Greenslade, L. Cullen et al., "Validation of presentation and $3 \mathrm{~h}$ high-sensitivity troponin to rule-in and rule-out acute myocardial infarction," Heart, vol. 102, no. 16, pp. 1270-1278, 2016.

[29] J. Boeddinghaus, T. Nestelberger, R. Twerenbold et al., "Impact of age on the performance of the ESC 0/1h-algorithms for early diagnosis of myocardial infarction," European Heart Journal, vol. 39, no. 42, pp. 3780-3794, 2018.

[30] M. Mueller-Hennessen, B. Lindahl, E. Giannitsis et al., "Diagnostic and prognostic implications using age- and gender-specific cut-offs for high-sensitivity cardiac troponin T - Sub-analysis from the TRAPID-AMI study," International Journal of Cardiology, vol. 209, pp. 26-33, 2016.

[31] D. M. Kimenai, E. B. N. J. Janssen, K. M. Eggers et al., "Sexspecific versus overall clinical decision limits for cardiac troponin I and $\mathrm{T}$ for the diagnosis of acute myocardial infarction: a systematic review," Clinical Chemistry, vol. 64, no. 7, pp. 1034-1043, 2018.

[32] S. Yang, W. Huai, R. Qiao et al., "Age and gender tailored cutoff value of hs-cTnT contributes to rapidly diagnose acute myocardial infarction in chest pain patients," Clinical Laboratory, vol. 62, no. 8, pp. 1451-1459, 2016.

[33] M. Rubini Gimenez, R. Twerenbold, T. Reichlin et al., "Direct comparison of high-sensitivity-cardiac troponin I vs. T for the early diagnosis of acute myocardial infarction," European Heart Journal, vol. 35, no. 34, pp. 2303-2311, 2014.

[34] L. J. J. Klinkenberg, K. Wildi, N. van der Linden et al., "Diurnal rhythm of cardiac troponin: consequences for the diagnosis of acute myocardial infarction," Clinical Chemistry, vol. 62, no. 12, pp. 1602-1611, 2016.

[35] K. Wildi, H. Singeisen, R. Twerenbold et al., "Circadian rhythm of cardiac troponin I and its clinical impact on the diagnostic accuracy for acute myocardial infarction," International Journal of Cardiology, vol. 270, pp. 14-20, 2018.

[36] P. A. Heidenreich, T. Alloggiamento, K. M. McDonald, A. S. Go, M. A. Hlatky, and K. Melsop, "The prognostic value of troponin in patients with non-ST elevation acute coronary syndromes: a meta-analysis," Journal of the American College of Cardiology, vol. 38, no. 2, pp. 478-485, 2001.

[37] B. M. Everett, T. Zeller, R. J. Glynn, P. M. Ridker, and S. Blankenberg, "High-sensitivity cardiac troponin I and B-type natriuretic Peptide as predictors of vascular events in primary prevention: impact of statin therapy," Circulation, vol. 131, no. 21, pp. 1851-1860, 2015. 
[38] Á. Árnadóttir, K. R. Vestergaard, J. Pallisgaard et al., "Highsensitivity cardiac troponin $\mathrm{T}$ is superior to troponin $\mathrm{I}$ in the prediction of mortality in patients without acute coronary syndrome," International Journal of Cardiology, vol. 259, pp. 186-191, 2018.

[39] P. C. Y. Wong, J. Guo, and A. Zhang, "The renal and cardiovascular effects of natriuretic peptides," Advances in Physiology Education, vol. 41, no. 2, pp. 179-185, 2017.

[40] L. B. Daniels and A. S. Maisel, "Natriuretic peptides," Journal of the American College of Cardiology, vol. 50, no. 25, pp. 2357-2368, 2007.

[41] L. R. Potter, "Natriuretic peptide metabolism, clearance and degradation," FEBS Journal, vol. 278, no. 11, pp. 1808-1817, 2011.

[42] J. P. Goetze, L. H. Hansen, D. Terzic et al., "Atrial natriuretic peptides in plasma," Clinica Chimica Acta, vol. 443, pp. 25-28, 2015.

[43] A. D. Struthers, "Introducing a new role for BNP: as a general indicator of cardiac structural disease rather than a specific indicator of systolic dysfunction only," Heart, vol. 87 , no. 2, pp. 97-98, 2002.

[44] H. K. Gaggin and J. L. Januzzi, "Biomarkers and diagnostics in heart failure," Biochimica et Biophysica Acta (BBA)Molecular Basis of Disease, vol. 1832, no. 12, pp. 2442-2450, 2013.

[45] M. Volpe, S. Rubattu, and J. Burnett Jr., "Natriuretic peptides in cardiovascular diseases: current use and perspectives," European Heart Journal, vol. 35, no. 7, pp. 419-425, 2014.

[46] P. Ponikowski, A. A. Voors, S. D. Anker et al., "ESC Guidelines for the diagnosis and treatment of acute and chronic heart failure: the Task Force for the diagnosis and treatment of acute and chronic heart failure of the European Society of Cardiology (ESC)Developed with the special contribution of the Heart Failure Association (HFA) of the ESC," European Heart Journal, vol. 37, no. 27, pp. 2129-2200, 2016.

[47] M. Rubini Gimenez, R. Twerenbold, and C. Mueller, "Beyond cardiac troponin: recent advances in the development of alternative biomarkers for cardiovascular disease," Expert Review of Molecular Diagnostics, vol. 15, no. 4, pp. 547-556, 2015.

[48] F. H. Rutten and A. W. Hoes, "Natriuretic peptide tests in suspected acute heart failure," BMJ, vol. 350, no. mar04 22, p. h1164, 2015.

[49] C. Madamanchi, H. Alhosaini, A. Sumida, and M. S. Runge, "Obesity and natriuretic peptides, BNP and NT-proBNP: mechanisms and diagnostic implications for heart failure," International Journal of Cardiology, vol. 176, no. 3, pp. 611-617, 2014.

[50] A. Bayes-Genis, C. DeFilippi, and J. L. Januzzi Jr., "Understanding amino-terminal pro-B-type natriuretic peptide in obesity," The American Journal of Cardiology, vol. 101, no. 3, pp. 89-94, 2008.

[51] E. Roberts, A. J. Ludman, K. Dworzynski et al., "The diagnostic accuracy of the natriuretic peptides in heart failure: systematic review and diagnostic meta-analysis in the acute care setting," BMJ, vol. 350, 2015.

[52] G. M. Felker, V. Hasselblad, A. F. Hernandez, and C. M. O'Connor, "Biomarker-guided therapy in chronic heart failure: a meta-analysis of randomized controlled trials," American Heart Journal, vol. 158, no. 3, pp. 422-430, 2009.

[53] R. W. Troughton, C. M. Frampton, H.-P. Brunner-La Rocca et al., "Effect of B-type natriuretic peptide-guided treatment of chronic heart failure on total mortality and hospitalization: an individual patient meta-analysis," European Heart Journal, vol. 35, no. 23, pp. 1559-1567, 2014.

[54] T. Ohkuma, M. Jun, M. Woodward et al., "Cardiac stress and inflammatory markers as predictors of heart failure in patients with type 2 diabetes: the ADVANCE trial," Diabetes Care, vol. 40, no. 9, pp. 1203-1209, 2017.

[55] P. Ballo, I. Betti, A. Barchielli et al., "Prognostic role of $\mathrm{N}$-terminal pro-brain natriuretic peptide in asymptomatic hypertensive and diabetic patients in primary care: impact of age and gender," Clinical Research in Cardiology, vol. 105, no. 5, pp. 421-431, 2016.

[56] D. Poldermans, S. E. Hoeks, and H. H. Feringa, "Pre-operative risk assessment and risk reduction before surgery," Journal of the American College of Cardiology, vol. 51, no. 20, pp. 1913-1924, 2008.

[57] R. N. Rodseth, B. M. Biccard, Y. Le Manach et al., "The prognostic value of pre-operative and post-operative B-type natriuretic peptides in patients undergoing noncardiac surgery: B-type natriuretic peptide and $\mathrm{N}$-terminal fragment of pro-B-type natriuretic peptide: a systematic review and individual patient data meta-analysis," Journal of the American College of Cardiology, vol. 63, no. 2, pp. 170-180, 2014.

[58] D. Schellings, A. Adiyaman, J.-H. Dambrink et al., "Predictive value of NT-proBNP for 30-day mortality in patients with non-ST-elevation acute coronary syndromes: a comparison with the GRACE and TIMI risk scores," Vascular Health and Risk Management, vol. 12, pp. 471-476, 2016.

[59] D. A. Morrow, C. P. Cannon, R. L. Jesse et al., "National Academy of Clinical Biochemistry Laboratory Medicine Practice Guidelines: clinical characteristics and utilization of biochemical markers in acute coronary syndromes," Clinical Chemistry, vol. 115, no. 13, pp. 356-375, 2007.

[60] K. Thygesen, J. S. Alpert, A. S. Jaffe et al., "Fourth universal definition of myocardial infarction (2018)," Journal of the American College of Cardiology, vol. 72, no. 18, pp. 22312264, 2018.

[61] G. S. Hillis, P. Welsh, J. Chalmers et al., "The relative and combined ability of high-sensitivity cardiac troponin $\mathrm{T}$ and $\mathrm{N}$-terminal pro-B-type natriuretic peptide to predict cardiovascular events and death in patients with type 2 diabetes," Diabetes Care, vol. 37, no. 1, pp. 295-303, 2014.

[62] R. Klingenberg, S. Aghlmandi, L. Räber et al., "Improved risk stratification of patients with acute coronary syndromes using a combination of hsTnT, NT-proBNP and hsCRP with the GRACE score," European Heart Journal: Acute Cardiovascular Care, vol. 7, no. 2, pp. 129-138, 2018.

[63] C. Puelacher, M. Wagener, U. Honegger et al., "Combining high-sensitivity cardiac troponin and B-type natriuretic peptide in the detection of inducible myocardial ischemia," Clinical Biochemistry, vol. 52, pp. 33-40, 2018.

[64] G. L. Reynoso-Villalpando, J. R. Padilla-Gutiérrez, A. Valdez-Haro et al., "Relationship between C-reactive protein serum concentration and the $1846 \mathrm{C}>\mathrm{T}$ (rs1205) polymorphism in patients with acute coronary syndrome from Western Mexico," Genetic Testing and Molecular Biomarkers, vol. 21, no. 5, pp. 334-340, 2017.

[65] S. De Servi, M. Mariani, G. Mariani, and A. Mazzone, "Creactive protein increase in unstable coronary disease - cause or effect?," Journal of the American College of Cardiology, vol. 46, no. 8, pp. 1496-1502, 2005.

[66] D. Afzali, M. Erren, H.-J. Pavenstädt et al., "Impact of copeptin on diagnosis, risk stratification, and intermediate- 
term prognosis of acute coronary syndromes," Clinical Research in Cardiology, vol. 102, no. 10, pp. 755-763, 2013.

[67] K. Yalta, T. Yalta, N. Sivri, and E. Yetkin, "Copeptin and cardiovascular disease: a review of a novel neurohormone," International Journal of Cardiology, vol. 167, no. 5, pp. 1750-1759, 2013.

[68] C. Folli, D. Consonni, M. Spessot et al., "Diagnostic role of copeptin in patients presenting with chest pain in the emergency room," European Journal of Internal Medicine, vol. 24, no. 2, pp. 189-193, 2013.

[69] C. H. Nickel, R. Bingisser, and N. G. Morgenthaler, "The role of copeptin as a diagnostic and prognostic biomarker for risk stratification in the emergency department," BMC Medicine, vol. 10, no. 1, 2012.

[70] J. H. Jeong, Y. H. Seo, J. Y. Ahn et al., "Performance of copeptin for early diagnosis of acute myocardial infarction in an emergency department setting," Annals of Laboratory Medicine, vol. 40, no. 1, pp. 7-14, 2020.

[71] M. Abd El Baky Mahmoud, M. A. A. Shaaban, and A. Ali Ramzy, "Clinical role of serum Copeptin in acute coronary syndrome," The Egyptian Heart Journal, vol. 70, no. 3, pp. 155-159, 2018.

[72] T. Raskovalova, R. Twerenbold, P. O. Collinson et al., "Diagnostic accuracy of combined cardiac troponin and copeptin assessment for early rule-out of myocardial infarction: a systematic review and meta-analysis," European Heart Journal: Acute Cardiovascular Care, vol. 3, no. 1, pp. 18-27, 2014.

[73] Z. Pozsonyi, Z. Förhécz, T. Gombos, I. Karádi, L. Jánoskuti, and Z. Prohászka, "Copeptin (C-terminal pro arginine-vasopressin) is an independent long-term prognostic marker in heart failure with reduced ejection fraction," Heart, Lung and Circulation, vol. 24, no. 4, pp. 359-367, 2015.

[74] A. Alquezar, M. Santalo, M. Rizzi et al., "Combined highsensitivity copeptin and troponin $\mathrm{T}$ evaluation for the diagnosis of non-ST elevation acute coronary syndrome in the emergency department," Emergencias, vol. 29, no. 4, pp. 237-244, 2017.

[75] C. Liebetrau, J. Hoffmann, O. Dörr et al., "Release kinetics of inflammatory biomarkers in a clinical model of acute myocardial infarction," Circulation Research, vol. 116, no. 5, pp. 867-875, 2015.

[76] J. Kaminska, O. M. Koper, E. Siedlecka-Czykier, J. Matowicka-Karna, J. Bychowski, and H. Kemona, "The utility of inflammation and platelet biomarkers in patients with acute coronary syndromes," Saudi Journal of Biological Sciences, vol. 25, no. 7, pp. 1263-1271, 2018.

[77] C. Held, H. D. White, R. A. H. Stewart et al., "Inflammatory biomarkers interleukin- 6 and C-reactive protein and outcomes in stable coronary heart disease: experiences from the STABILITY (stabilization of atherosclerotic plaque by initiation of darapladib therapy) trial," Journal of the American Heart Association, vol. 6, no. 10, 2017.

[78] C. L. Fanola, D. A. Morrow, C. P. Cannon et al., "Interleukin6 and the risk of adverse outcomes in patients after an acute coronary syndrome: observations from the SOLID-TIMI 52 (stabilization of plaque using darapladib-thrombolysis in myocardial infarction 52) trial," J Am Heart Assoc, vol. 6, no. 10, 2017.

[79] O. Kleveland, G. Kunszt, M. Bratlie et al., "Effect of a single dose of the interleukin- 6 receptor antagonist tocilizumab on inflammation and troponin T release in patients with nonST-elevation myocardial infarction: a double-blind, randomized, placebo-controlled phase 2 trial," European Heart Journal, vol. 37, no. 30, pp. 2406-2413, 2016.

[80] P. Napoleão, M. M. Carmo, and T. Pinheiro, "Prognostic evaluation of soluble CD40L in acute myocardial infarction: is not fancy, is science!," Annals of Translational Medicine, vol. 5, no. 4, p. 90, 2017.

[81] B. Y. Setianto, A. B. Hartopo, P. P. R. Gharini, D. W. Anggrahini, and B. Irawan, "Circulating soluble CD40 ligand mediates the interaction between neutrophils and platelets in acute coronary syndrome," Heart and Vessels, vol. 25, no. 4, pp. 282-287, 2010.

[82] P. Napoleão, M. d. C. Monteiro, L. B. P. Cabral et al., "Changes of soluble CD40 ligand in the progression of acute myocardial infarction associate to endothelial nitric oxide synthase polymorphisms and vascular endothelial growth factor but not to platelet CD62P expression," Translational Research, vol. 166, no. 6, pp. 650-659, 2015.

[83] D. Tousoulis, C. Antoniades, A. Nikolopoulou et al., "Interaction between cytokines and SCD40L in patients with stable and unstable coronary syndromes," European Journal of Clinical Investigation, vol. 37, no. 8, pp. 623-628, 2007.

[84] P. Napoleão, L. B. P. Cabral, M. Selas et al., "Stratification of ST-elevation myocardial infarction patients based on soluble CD40L longitudinal changes," Translational Research, vol. 176, pp. 95-104, 2016.

[85] H. Pusuroglu, O. Akgul, M. Erturk et al., "Predictive value of elevated soluble CD40 ligand in patients undergoing primary angioplasty for ST-segment elevation myocardial infarction," Coronary Artery Disease, vol. 25, no. 7, pp. 558-564, 2014.

[86] Q. Kang, X. Li, M. Yang, T. Fernando, and Z. Wan, "Galectin-3 in patients with coronary heart disease and atrial fibrillation," Clinica Chimica Acta, vol. 478, pp. 166-170, 2018.

[87] G. Bivona, C. Bellia, B. Lo Sasso et al., "Short-term changes in gal 3 circulating levels after acute myocardial infarction," Archives of Medical Research, vol. 47, no. 7, pp. 521-525, 2016.

[88] B. French, L. Wang, B. Ky et al., "Prognostic value of galectin-3 for adverse outcomes in chronic heart failure," Journal of Cardiac Failure, vol. 22, no. 4, pp. 256-262, 2016.

[89] L. C. van Vark, I. Lesman-Leegte, S. J. Baart et al., "Prognostic value of serial galectin-3 measurements in patients with acute heart failure," Journal of the American Heart Association, vol. 6, no. 12, 2017.

[90] C. Zivlas, F. Triposkiadis, S. Psarras et al., "Left atrial volume index in patients with heart failure and severely impaired left ventricular systolic function: the role of established echocardiographic parameters, circulating cystatin $\mathrm{C}$ and galectin-3," Therapeutic Advances in Cardiovascular Disease, vol. 11, no. 11, pp. 283-295, 2017.

[91] K. Liu, Q. Tang, X. Zhu, and X. Yang, "IL-37 increased in patients with acute coronary syndrome and associated with a worse clinical outcome after ST-segment elevation acute myocardial infarction," Clinica Chimica Acta, vol. 468, pp. 140-144, 2017.

[92] T. Yang, F. Fang, Y. Chen et al., "Elevated plasma interleukin-37 playing an important role in acute coronary syndrome through suppression of ROCK activation," Oncotarget, vol. 8, no. 6, pp. 9686-9695, 2017.

[93] L. Wallentin, C. Held, P. W. Armstrong et al., "Lipoproteinassociated phospholipase A2 activity is a marker of risk but not a useful target for treatment in patients with stable coronary heart disease," Journal of the American Heart Association, vol. 5, no. 6, 2016. 
[94] L. Carrier, G. Bonne, E. Bahrend et al., "Organization and sequence of human cardiac myosin binding protein $\mathrm{C}$ gene (MYBPC3) and identification of mutations predicted to produce truncated proteins in familial hypertrophic cardiomyopathy," Circulation Research, vol. 80, no. 3, pp. 427-434, 1997.

[95] T. E. Kaier, B. Alaour, and M. Marber, "Cardiac myosinbinding prot0065in C-from bench to improved diagnosis of acute myocardial infarction," Cardiovascular Drugs and Therapy, vol. 33, no. 2, pp. 221-230, 2019.

[96] T. E. Kaier, B. Alaour, and M. Marber, "Cardiac myosinbinding protein C: how a novel biomarker could transform chest pain triage," Biomarkers in Medicine, vol. 12, no. 8, pp. 823-826, 2018.

[97] T. E. Kaier, R. Twerenbold, C. Puelacher et al., "Direct comparison of cardiac myosin-binding protein $\mathrm{C}$ with cardiac troponins for the early diagnosis of acute myocardial infarction," Circulation, vol. 136, no. 16, pp. 1495-1508, 2017.

[98] A. M. Dupuy, J. P. Cristol, N. Kuster et al., "Performances of the heart fatty acid protein assay for the rapid diagnosis of acute myocardial infarction in ED patients," The American Journal of Emergency Medicine, vol. 33, no. 3, pp. 326-330, 2015.

[99] L. Agnello, G. Bivona, G. Novo et al., "Heart-type fatty acid binding protein is a sensitive biomarker for early AMI detection in troponin negative patients: a pilot study," Scandinavian Journal of Clinical and Laboratory Investigation, vol. 77, no. 6, pp. 428-432, 2017.

[100] C. B. Van Hise, J. H. Greenslade, W. Parsonage, M. Than, J. Young, and L. Cullen, "External validation of heart-type fatty acid binding protein, high-sensitivity cardiac troponin, and electrocardiography as rule-out for acute myocardial infarction," Clinical Biochemistry, vol. 52, pp. 161-163, 2018.

[101] J. M. Young, J. W. Pickering, P. M. George et al., "Heart Fatty Acid Binding Protein and cardiac troponin: development of an optimal rule-out strategy for acute myocardial infarction," BMC Emergency Medicine, vol. 16, no. 1, p. 34, 2016.

[102] A. Vupputuri, S. Sekhar, S. Krishnan, K. Venugopal, and K. U. Natarajan, "Heart-type fatty acid-binding protein $(\mathrm{H}-$ FABP) as an early diagnostic biomarker in patients with acute chest pain," Indian Heart Journal, vol. 67, no. 6, pp. 538-542, 2015.

[103] C.-R. Qiu, Q. Fu, J. Sui et al., "Serum endothelial cell-specific molecule 1 (endocan) levels in patients with acute myocardial infarction and its clinical significance," Angiology, vol. 68, no. 4, pp. 354-359, 2017.

[104] C.-Z. Gao, Q.-Q. Ma, J. Wu et al., "Comparison of the effects of ticagrelor and clopidogrel on inflammatory factors, vascular endothelium functions and short-term prognosis in patients with acute ST-segment elevation myocardial infarction undergoing emergency percutaneous coronary intervention: a pilot study," Cellular Physiology and Biochemistry, vol. 48, no. 1, pp. 385-396, 2018.

[105] H. Kundi, A. Balun, H. Cicekcioglu et al., "Admission endocan level may be a useful predictor for in-hospital mortality and coronary severity index in patients with STsegment elevation myocardial infarction," Angiology, vol. 68, no. 1, pp. 46-51, 2017.

[106] C. Qiu, J. Sui, Q. Zhang, P. Wei, P. Wang, and Q. Fu, "Relationship of endothelial cell-specific molecule 1 level in stress hyperglycemia patients with acute ST-segment elevation myocardial infarction: a pilot study," Angiology, vol. 67, no. 9, pp. 829-834, 2016.
[107] J. Wasilewski, P. Desperak, M. Hawranek et al., "Prognostic implications of mean platelet volume on short- and longterm outcomes among patients with non-ST-segment elevation myocardial infarction treated with percutaneous coronary intervention: a single-center large observational study," Platelets, vol. 27, no. 5, pp. 452-458, 2016.

[108] M. Tajstra, M. Hawranek, P. Desperak et al., "Medium platelet volume as a noninvasive predictor of chronic total occlusion in non-infarct artery in patients with non-STsegment elevation myocardial infarction and multivessel coronary artery disease," International Journal of Cardiology, vol. 228, pp. 594-598, 2017.

[109] I. Bolat, O. Akgul, H. A. Cakmak et al., "The prognostic value of admission mean platelet volume to platelet count ratio in patients with ST-segment elevation myocardial infarction undergoing primary percutaneous coronary intervention," kardiologia Polska, vol. 74, no. 4, pp. 346-355, 2016.

[110] T. Yu, Y. Dong, Z. Sun, and Z. Sun, "Comparison of prognostic significance of mean platelet volume/platelet count with GRACE for long-term prognosis in patients with non-ST-segment elevation myocardial infarction undergoing percutaneous coronary intervention," International Journal of Cardiology, vol. 228, pp. 335-340, 2017.

[111] C. Tian, J. Song, D. He, J. Wu, Z. Sun, and Z. Sun, "Predictive value of mean platelet volume/platelet count for prognosis in acute myocardial infarction," International Heart Journal, vol. 59, no. 2, pp. 286-292, 2018.

[112] S. Li, L. Z. Guo, M. H. Kim, J.-Y. Han, and V. Serebruany, "Platelet microRNA for predicting acute myocardial infarction," Journal of Thrombosis and Thrombolysis, vol. 44, no. 4, pp. 556-564, 2017.

[113] G. Bergers, A. Reikerstorfer, S. Braselmann, P. Graninger, and M. Busslinger, "Alternative promoter usage of the Fosresponsive gene Fit-1 generates mRNA isoforms coding for either secreted or membrane-bound proteins related to the IL-1 receptor," The EMBO Journal, vol. 13, no. 5, pp. 1176-1188, 1994.

[114] C. Schernthaner, M. Lichtenauer, B. Wernly et al., "Multibiomarker analysis in patients with acute myocardial infarction," European Journal of Clinical Investigation, vol. 47, no. 9, pp. 638-648, 2017.

[115] D. Jha, L. Goenka, T. Ramamoorthy, M. Sharma, V. E. Dhandapani, and M. George, "Prognostic role of soluble ST2 in acute coronary syndrome with diabetes," European Journal of Clinical Investigation, vol. 48, no. 9, p. e12994, 2018.

[116] Y.-P. Wang, J.-H. Wang, X.-L. Wang et al., "Roles of ST2, IL33 and BNP in predicting major adverse cardiovascular events in acute myocardial infarction after percutaneous coronary intervention," Journal of Cellular and Molecular Medicine, vol. 21, no. 11, pp. 2677-2684, 2017.

[117] C. W. Yancy, M. Jessup, B. Bozkurt et al., "2017 ACC/AHA/ HFSA focused update of the 2013 ACCF/AHA guideline for the management of heart failure: a report of the American college of Cardiology/American heart association task force on clinical practice guidelines and the heart failure society of America," Circulation, vol. 136, no. 6, pp. e137-e161, 2017.

[118] K. Seki, S. Sanada, A. Y. Kudinova et al., "Interleukin-33 prevents apoptosis and improves survival after experimental myocardial infarction through ST2 signaling," Circulation: Heart Failure, vol. 2, no. 6, pp. 684-691, 2009.

[119] B. Chen, J. Geng, S.-X. Gao, W.-W. Yue, and Q. Liu, "Eplerenone modulates interleukin-33/sST2 signaling and IL-1 $\beta$ in left ventricular systolic dysfunction after acute 
myocardial infarction," Journal of Interferon \& Cytokine Research, vol. 38, no. 3, pp. 137-144, 2018.

[120] A. Lax, J. Sanchez-Mas, M. C. Asensio-Lopez et al., "Mineralocorticoid receptor antagonists modulate galectin-3 and interleukin-33/ST2 signaling in left ventricular systolic dysfunction after acute myocardial infarction," JACC: Heart Failure, vol. 3, no. 1, pp. 50-58, 2015.

[121] J. Sánchez-Más, A. Lax, M. D. C. Asensio-López et al., "Modulation of IL-33/ST2 system in postinfarction heart failure: correlation with cardiac remodelling markers," $E \mathbf{u}$ ropean Journal of Clinical Investigation, vol. 44, no. 7, pp. 643-651, 2014.

[122] N. S. Luo, H. F. Zhang, P. M. Liu et al., "Diagnostic value of combining serum soluble ST2 and interleukin-33 for heart failure patients with preserved left ventricular ejection fraction," Zhonghua Xin Xue Guan Bing Za Zhi, vol. 45, no. 3, pp. 198-203, 2017.

[123] J. Lupón, H. K. Gaggin, M. de Antonio et al., "Biomarkerassist score for reverse remodeling prediction in heart failure: the ST2-R2 score," International Journal of Cardiology, vol. 184, pp. 337-343, 2015.

[124] J. Lupón, S. Sanders-van Wijk, J. L. Januzzi et al., "Prediction of survival and magnitude of reverse remodeling using the ST2-R2 score in heart failure: a multicenter study," International Journal of Cardiology, vol. 204, pp. 242-247, 2016.

[125] C. G. Bahuleyan, G. K. Alummoottil, J. Abdullakutty et al., "Prognostic value of soluble ST2 biomarker in heart failure patients with reduced ejection fraction-a multicenter study," Indian Heart Journal, vol. 70, no. 1, pp. S79-S84, 2018.

[126] T. Mueller, A. Gegenhuber, I. Leitner, W. Poelz, M. Haltmayer, and B. Dieplinger, "Diagnostic and prognostic accuracy of galectin-3 and soluble ST2 for acute heart failure," Clinica Chimica Acta, vol. 463, pp. 158-164, 2016.

[127] I. S. Anand, T. S. Rector, M. Kuskowski, J. Snider, and J. N. Cohn, "Prognostic value of soluble ST2 in the valsartan heart failure trial," Circulation: Heart Failure, vol. 7, no. 3, pp. 418-426, 2014.

[128] W. H. W. Tang, Y. Wu, J. L. Grodin et al., "Prognostic value of baseline and changes in circulating soluble ST2 levels and the effects of nesiritide in acute decompensated heart failure," JACC: Heart Failure, vol. 4, no. 1, pp. 68-77, 2016.

[129] A. Bayes-Genis, M. de Antonio, J. Vila et al., "Head-to-head comparison of 2 myocardial fibrosis biomarkers for longterm heart failure risk stratification: ST2 versus galectin-3," Journal of the American College of Cardiology, vol. 63, no. 2, pp. 158-166, 2014.

[130] L. Tang, Z.-F. Fang, S.-H. Zhou et al., "Association of serum cystatin $\mathrm{C}$ levels with myocardial perfusion and cardiac functional recovery in patients with anterior wall ST elevation myocardial infarction treated with primary coronary intervention," Heart and Vessels, vol. 31, no. 9, pp. 14561466, 2016

[131] S. Correa, D. A. Morrow, E. Braunwald et al., "Cystatin C for risk stratification in patients after an acute coronary syndrome," Journal of the American Heart Association, vol. 7, no. 20, p. e009077, 2018.

[132] G. Shen, H. Zhu, H. Ding et al., "Increased cystatin C level in ST-elevation myocardial infarction predisposes the prognosis of angioplasty," The American Journal of the Medical Sciences, vol. 355, no. 6, pp. 530-536, 2018.

[133] O. Akgul, H. Uyarel, M. Ergelen et al., "Predictive value of elevated cystatin $\mathrm{C}$ in patients undergoing primary angioplasty for ST-elevation myocardial infarction," Journal of Critical Care, vol. 28, no. 5, pp. 882 e13-882 e20, 2013.
[134] S. Chen, Y. Tang, and X. Zhou, "Cystatin C for predicting allcause mortality and rehospitalization in patients with heart failure: a meta-analysis," Bioscience Reports, vol. 39, no. 2, 2019.

[135] Y. Devaux, M. Vausort, E. Goretti et al., "Use of circulating microRNAs to diagnose acute myocardial infarction," Clinical Chemistry, vol. 58, no. 3, pp. 559-567, 2012.

[136] Y. D’Alessandra, P. Devanna, F. Limana et al., "Circulating microRNAs are new and sensitive biomarkers of myocardial infarction," European Heart Journal, vol. 31, no. 22, pp. 2765-2773, 2010.

[137] T. Adachi, M. Nakanishi, Y. Otsuka et al., "Plasma MicroRNA 499 as a biomarker of acute myocardial infarction," Clinical Chemistry, vol. 56, no. 7, pp. 1183-1185, 2010.

[138] S. Ikeda and W. T. Pu, "Expression and function of MicroRNAs in heart disease," Current Drug Targets, vol. 11, no. 8, pp. 913-925, 2010.

[139] O. Nagy, S. Baráth, and A. Ujfalusi, "The role of microRNAs in congenital heart disease," EJIFCC, vol. 30, no. 2, pp. 165-178, 2019.

[140] Y. Kuwabara, K. Ono, T. Horie et al., "Increased microRNA-1 and microRNA-133a levels in serum of patients with cardiovascular disease indicate myocardial damage," Circulation: Cardiovascular Genetics, vol. 4, no. 4, pp. 446-454, 2011.

[141] M. Li, Y.-F. Wang, X.-C. Yang et al., "Circulating long noncoding RNA LIPCAR acts as a novel biomarker in patients with ST-segment elevation myocardial infarction," Medical Science Monitor, vol. 24, pp. 5064-5070, 2018.

[142] L. Gao, Y. Liu, S. Guo et al., "Circulating long noncoding RNA HOTAIR is an essential mediator of acute myocardial infarction," Cellular Physiology and Biochemistry, vol. 44, no. 4, pp. 1497-1508, 2017.

[143] C. Y. Sun, H. Jiang, Z. G. Sun, Y. F. Gui, and H. Y. Xia, "Identification of long non-coding RNAs biomarkers for early diagnosis of myocardial infarction from the dysregulated coding-non-coding co-expression network," Oncotarget, vol. 7, no. 45, pp. 73541-73551, 2016.

[144] R. Kumarswamy, C. Bauters, I. Volkmann et al., "Circulating long noncoding RNA, LIPCAR, predicts survival in patients with heart failure," Circulation Research, vol. 114, no. 10, pp. 1569-1575, 2014.

[145] M. Vausort, D. R. Wagner, and Y. Devaux, "Long noncoding RNAs in patients with acute myocardial infarction," Circulation Research, vol. 115, no. 7, pp. 668-677, 2014.

[146] N. D'Onofrio, L. Servillo, and M. L. Balestrieri, "SIRT1 and SIRT6 signaling pathways in cardiovascular disease protection," Antioxidants \& Redox Signaling, vol. 28, no. 8, pp. 711-732, 2018.

[147] Y. Hu, L. Wang, S. Chen et al., "Association between the SIRT1 mRNA expression and acute coronary syndrome," Journal of Atherosclerosis and Thrombosis, vol. 22, no. 2, pp. 165-182, 2015.

[148] F. Akkafa, I. Halil Altiparmak, M. E. Erkus et al., "Reduced SIRT1 expression correlates with enhanced oxidative stress in compensated and decompensated heart failure," Redox Biology, vol. 6, pp. 169-173, 2015.

[149] V. H. R. Duarte, C. Miranda, M. S. Cruz et al., "TREML4 mRNA expression and polymorphisms in blood leukocytes are associated with atherosclerotic lesion extension in coronary artery disease," Scientific Reports, vol. 9, no. 1, p. 7229, 2019.

[150] V. N. Silbiger, A. D. Luchessi, R. D. C. Hirata et al., "Novel genes detected by transcriptional profiling from whole-blood 
cells in patients with early onset of acute coronary syndrome," Clinica Chimica Acta, vol. 421, pp. 184-190, 2013.

[151] A. Boufenzer, J. Lemarié, T. Simon et al., "TREM-1 mediates inflammatory injury and cardiac remodeling following myocardial infarction," Circulation Research, vol. 116, no. 11, pp. 1772-1782, 2015.

[152] J. E. Ho, A. Mahajan, M.-H. Chen et al., "Clinical and genetic correlates of growth differentiation factor 15 in the community," Clinical Chemistry, vol. 58, no. 11, pp. 1582-1591, 2012.

[153] D. W. Schopfer, I. A. Ku, M. Regan, and M. A. Whooley, "Growth differentiation factor 15 and cardiovascular events in patients with stable ischemic heart disease (the Heart and Soul Study)," American Heart Journal, vol. 167, no. 2, pp. 186-192, 2014.

[154] X. Wang, L.-L. Chen, and Q. Zhang, "Increased serum level of growth differentiation factor 15 (GDF-15) is associated with coronary artery disease," Cardiovascular Therapeutics, vol. 34, no. 3, pp. 138-143, 2016.

[155] S. Zhang, D. Dai, X. Wang et al., "Growth differentiation factor-15 predicts the prognoses of patients with acute coronary syndrome: a meta-analysis," BMC Cardiovascular Disorders, vol. 16, no. 1, 2016.

[156] S. Xie, L. Lu, and L. Liu, "Growth differentiation factor-15 and the risk of cardiovascular diseases and all-cause mortality: a meta-analysis of prospective studies," Clinical Cardiology, vol. 42, no. 5, pp. 513-523, 2019.

[157] L. B. Daniels, P. Clopton, G. A. Laughlin, A. S. Maisel, and E. Barrett-Connor, "Growth-differentiation factor-15 is a robust, independent predictor of 11-year mortality risk in community-dwelling older adults: the Rancho Bernardo Study," Circulation, vol. 123, no. 19, pp. 2101-2110, 2011.

[158] M. C. Bodde, M. P. J. Hermans, A. van der Laarse et al., "Growth differentiation factor-15 levels at admission provide incremental prognostic information on all-cause long-term mortality in ST-segment elevation myocardial infarction patients treated with primary percutaneous coronary intervention," Cardiology and Therapy, vol. 8, no. 1, pp. 29-41, 2019.

[159] H. Gutiérrez-Leonard, E. Martínez-Lara, A. E. Fierro-Macías et al., "Pregnancy-associated plasma protein-A (PAPP-A) as a possible biomarker in patients with coronary artery disease," Irish Journal of Medical Science (1971), vol. 186, no. 3, pp. 597-605, 2017.

[160] K. K. Iversen, A. S. Teisner, B. Teisner et al., "Pregnancy associated plasma protein A, a novel, quick, and sensitive marker in ST-elevation myocardial infarction," The American Journal of Cardiology, vol. 101, no. 10, pp. 1389-1394, 2008.

[161] J. Lund, Q.-P. Qin, T. Ilva et al., "Circulating pregnancyassociated plasma protein a predicts outcome in patients with acute coronary syndrome but no troponin I elevation," Circulation, vol. 108, no. 16, pp. 1924-1926, 2003.

[162] Y. Li, C. Zhou, X. Zhou, L. Li, and R. Hui, "Systemic review/ Meta-analysis pregnancy-associated plasma protein A predicts adverse vascular events in patients with coronary heart disease: a systematic review and meta-analysis," Archives of Medical Science, vol. 3, no. 3, pp. 389-397, 2013.

[163] B. C. Tan, Q. Liu, L. P. Yang et al., "Low expression of PRMT5 in peripheral blood may serve as a potential independent risk factor in assessments of the risk of stable CAD and AMI," BMC Cardiovascular Disorders, vol. 19, 2019.

[164] B. Tan, M. Liu, Y. Yang, L. Liu, and F. Meng, "Low expression of PIK3C2A gene: a potential biomarker to predict the risk of acute myocardial infarction," Medicine (Baltimore), vol. 98, no. 14, p. e15061, 2019.

[165] J. Kastrup, "Can YKL-40 be a new inflammatory biomarker in cardiovascular disease?," Immunobiology, vol. 217, no. 5, pp. 483-491, 2012.

[166] C. Angelidis, S. Deftereos, G. Giannopoulos et al., "Cystatin C: an emerging biomarker in cardiovascular disease," Current Topics in Medicinal Chemistry, vol. 13, no. 2, pp. 164179, 2013. 


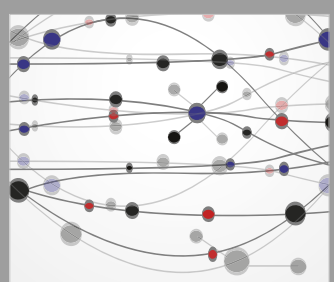

The Scientific World Journal
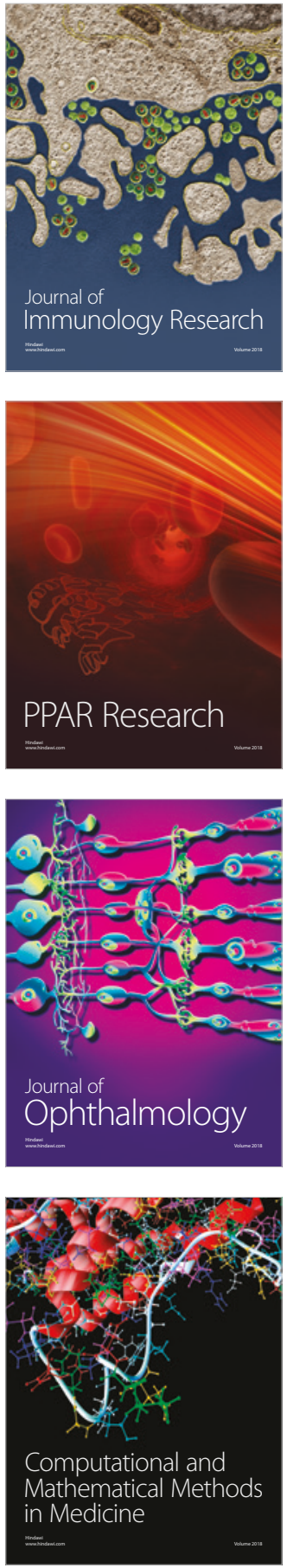

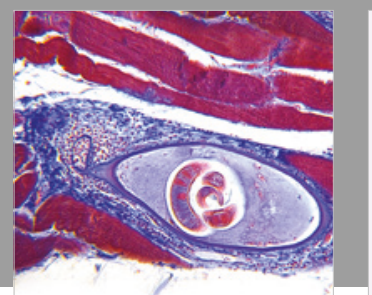

Gastroenterology Research and Practice

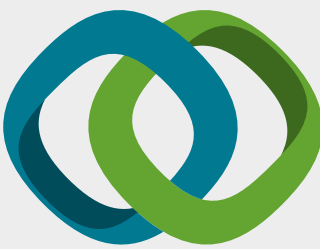

\section{Hindawi}

Submit your manuscripts at

www.hindawi.com
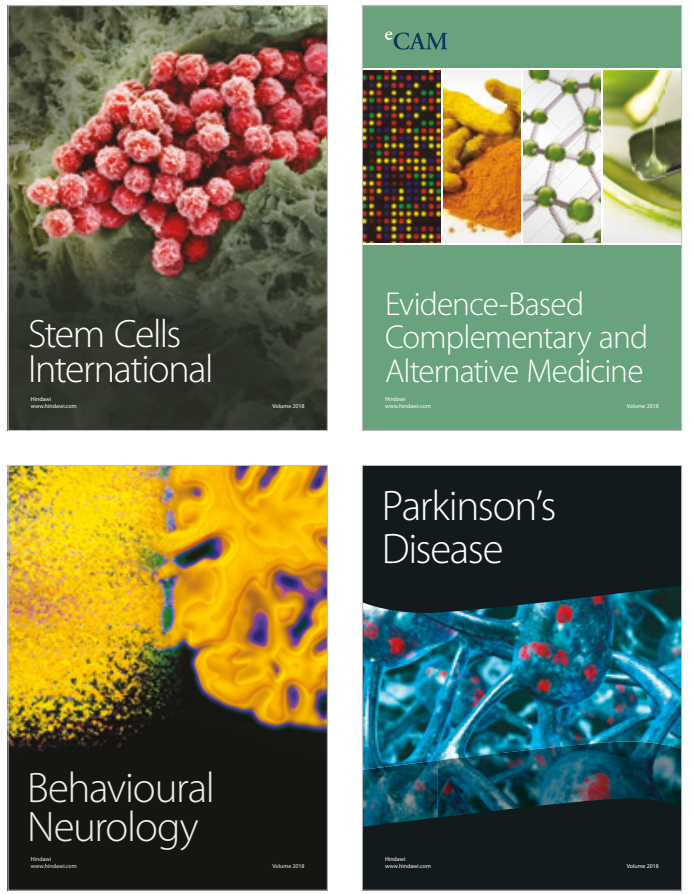

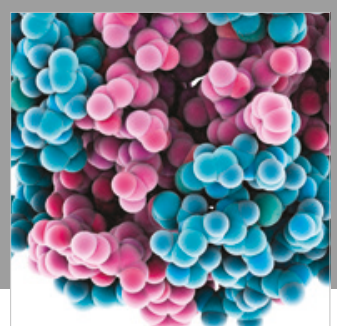

ournal of

Diabetes Research

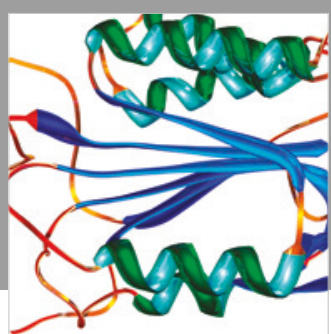

Disease Markers
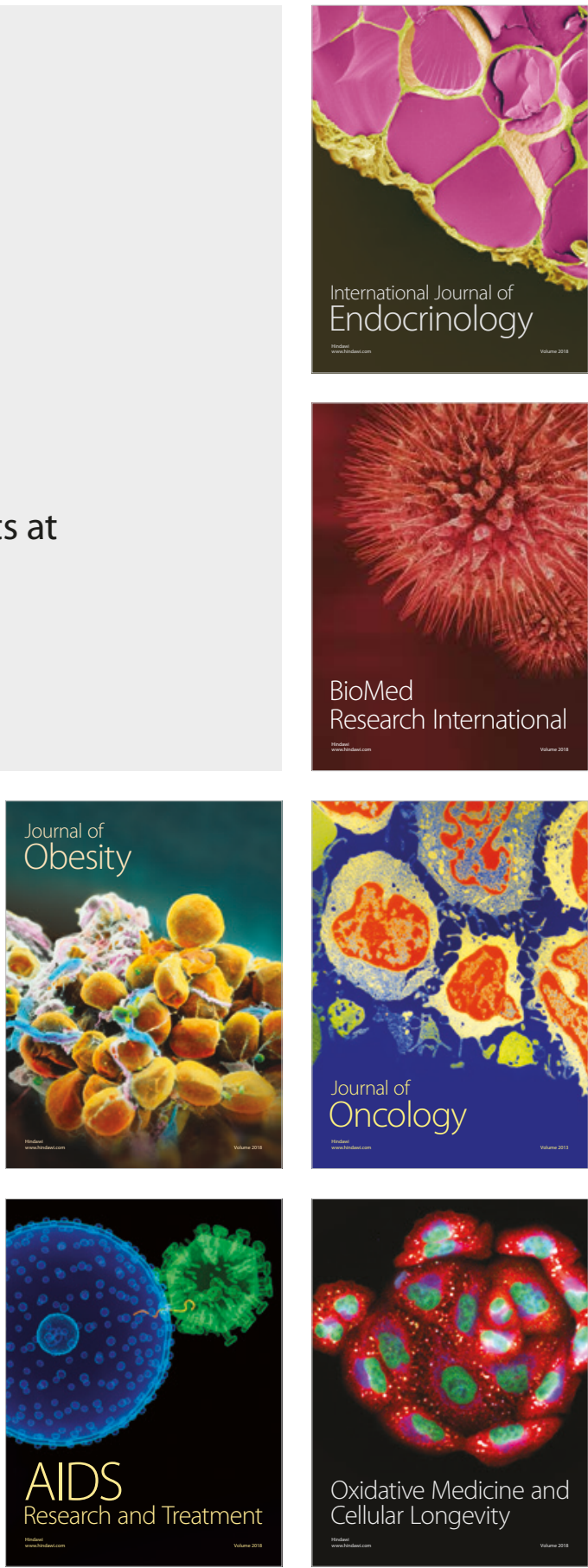